\title{
Analysing the decision making for agricultural risk assessment: An application of extreme value theory
}

\author{
Riaman $^{a^{*}}$, Sukono $^{\text {b }}$, Sudradjat Supian ${ }^{\mathrm{b}}$ and Noriszura Ismail ${ }^{\mathrm{c}}$
}

${ }^{a}$ Doctoral Student, Mathematics Study Program, Universitas Padjadjaran, Sumedang, Indonesia

${ }^{b}$ Department of Mathematics, Universitas Padjadjaran, Sumedang, Indonesia

${ }^{c}$ Department of Mathematical Sciences, Universiti Kebangsaan Malaysia, Malaysia

\begin{tabular}{l}
\hline C H R O N I C L E \\
\hline Article history: \\
Received September 28, 2020 \\
Received in revised format: \\
December 29, 2020 \\
Accepted February 2021 \\
Available online \\
February 3, 2021 \\
\hline Keywords: \\
Agricultural Insurance \\
Risk Assessment \\
Climate Variables \\
Extreme Value Theory
\end{tabular}

\section{Introduction}

Agriculture sector business, especially rice farming, is facing various risks, namely uncertainty. These risks include the risk of crop failure caused by climate change, such as temperature, flooding, drought (Mcleman and Smit, 2006). One way to manage these risks is through the Agricultural Insurance program, especially Rice Farmer Business Insurance. The Agricultural Insurance program aims to protect farmers from the risk of loss, with a guarantee that farmers will get working capital when farmers experience crop failure. From this guarantee of protection, if there is a crop failure, the farmer has the wealth for production costs in the next planting season.

The holding of the Agricultural Insurance program aims to protect farmers from losses through insurance companies. The objective of the Agricultural Insurance program is that farmers can be saved by obtaining compensation if they experience crop failure (Reyes et al., 2017). Risks covered in the Agricultural Insurance program include floods, drought and pest attacks. This paper will discuss weather-based risk determination which has rainfall, air temperature, and its effect on the number of rice yields. In conjunction with the previous elaboration, this paper investigates the decision making for agricultural risk assessment (climate variable) through the formulation of a risk model for agricultural insurance in Indonesia. This study utilised the climate variables such as air temperature, wind speed, maximum and minimum temperatures, and rainfall. This study uses Block Maxima and the Peak Over Threshold methods. Also, the extreme value theory focused on the generalised extreme value distributions (GEV).

\footnotetext{
* Corresponding author.

E-mail address: riaman@unpad.ac.id (Riaman)

(C) 2021 by the authors; licensee Growing Science, Canada

doi: $10.5267 /$ j.dsl.2021.2.003
} 


\section{Literature Review}

Issues of risk and agricultural insurance with various methods have been employed in several previous studies. Among other things, research on determining the number of premiums based on climate indices has been carried out by Sonia Akter (2016) with the climate parameters used as rainfall in the period 1966-2008 and data on the incidence of drought in the period 2001-2011 in Sliyeg District, Indramayu Regency (Akter et al., 2016). Calculation of the climate index is done by the Historical Burn method. Okine (2014) studied the climate index insurance prices using the Black-Scholes framework with a case study in Ghana literature. Also, the option approach price in determining farmland insurance premiums was presented by (Chicaíza and Cabedo, 2009). Furthermore, the CVaR model to determine agricultural insurance premiums, the results show that farmers' net income is significantly influenced by the agricultural insurance policies purchased and the level of risk aversion chosen (Chicaíza and Cabedo, 2009; Sukono et al., 2019; Syahril et al., 2019).

Teklewold et al. (2019) discussed the influence of gender and product design on farmers' preferences for weather-indexed crop insurance. They have determined a maximum limit of agricultural premiums with uncertainty theory. They also mentioned events (events) using the utility function of investment capital and view the number of losses faced by farmers as a random variable. It can be an alternative calculation of the maximum premium limit. Taib and Benth (2012), presented the pricing of weather insurance contracts based on the temperature index, the results show that there are significant differences between the burn and index pricing approach and the temperature modelling method. Stutley (2011) presented the importance of agricultural insurance in the Asia and Pacific region and exposure to climate hazards. Risk calculation is based on the climate index, using the Historical Burn method. Martin (2001) researched developing and pricing Precipitation Insurance to determine the price of agricultural land insurance premiums.

The problem of insurance premiums that mimic the option Payoff with a modification of the Black-Scholes option pricing formula was discussed in (Sturm et al., 2007). Also, Raucci et al. (2019) developed weather derivatives: evidence from the Brazilian soybean market, determining agricultural insurance premiums. An Innovative Damage Model for Crop Insurance, Combining Two Hazards into a Single Climatic Index, the calculation of the price of agricultural insurance premiums based on rainfall indexes using the Black Scholes scheme is discussed on Kapsambelis et al. (2019), but this study yields high enough premiums, making it less attractive for farmers to pay such a premium.

Burns and Prager (2018) discussed Crop Insurance as Commercial Crop Farm Decisions to Expand? An Analysis Using Panel Data from the Census of Agriculture" and determining the maximum limit of agricultural premiums using the theory of uncertainty (uncertainty theory). Berhane et al. (2020) presented the Option pricing of weather derivatives based on a stochastic daily rainfall model with Analogue Year component and determination of the price of rice insurance premiums based on rainfall indexes using the mixed exponential distribution generating method. Jindrová and Pacáková (2019) to discuss insurance risk management using the Catastrophe model.

Based on the description above, no studies have been found that produce reasonable premium prices. In this paper, a risk model formulation for multi-index based, rice agriculture insurance is carried out. The formulation will start from determining risk with CVaR, extreme value theory threshold limit, and yields with GDP, and finally choosing the risk size that will be used to determine the paddy farm insurance premium.

\section{Methodology}

Risk is a combination of the likelihood of certain events occurring and the possibility of damage resulting in losses (Pramono and Sukono, 2017). In this definition, there are two elements, namely uncertainty and loss. The intended loss is a financial risk that can be measured or valued in money, caused by the danger or failure of a function. Risk assessment is a product of the frequency value and the severity value of the risk. Risk is divided into several criteria, namely low, medium, high, and extreme. Risk assessment is a product of the frequency value and the severity value of the risk. For determining the risk category, whether it is low, medium, high or extreme, can be determined based on frequency and severity.

The risks faced in rice farming are extreme risks, which mean that the determination of risks in insurance for rice farming cannot be separated from determining thresholds or thresholds to determine the amount of risk. Two approaches are often used in models for extreme events, namely the Block Maxima and Peak Over Threshold (POT) methods. Threshold and magnitude of risk determined based on extreme deviations or Value at Risk (VaR) and plot data in accordance with Generalized Pareto Distribution (GPD).

\subsection{Block Maxima Method}

Block Maxima method is a method that identifies extreme values through maximum values from observational data grouped in a particular block or period. This approach only produces one extreme value in each block. The Block Maxima method 
refers to the distribution of GEV (Coles, 2001). In the Block Maxima method, observational data that has been divided into the same periods is observed for maximum data in each period.

For example, the number of yields per block is a sequence of random variables that have independent identically distributed

(iid) symbolised by a random variable: $X_{1}, X_{2}, X_{3}, \ldots, X_{n}$. The cumulative distribution function of the random variable $\mathrm{X}$ is defined as

$$
F_{X}(x)=P(X \leq x), x \geq 0
$$

If defined

$M_{\mathrm{n}}=\max \left(X_{1}, X_{2}, X_{3}, \ldots, X_{\mathrm{n}}\right)$, there are constants $\mathrm{c}_{\mathrm{n}}>0$ and $\mathrm{d}_{\mathrm{n}} \in \mathrm{R}$, so

$P\left\{\frac{M_{n}-d_{n}}{c_{n}} \leq x\right\} \rightarrow G(x), n \rightarrow \infty$

Then $G(X) \sim \exp \left\{-(1+\xi \chi)^{-\frac{1}{\xi}}\right\}$ where $\xi$ depends on the tail shape of the distribution. Another way, form $P\left\{\frac{M_{n}-d_{n}}{c_{n}} \leq x\right\} \rightarrow G(x), n \rightarrow \infty$ can be written as a limit distribution as follows

$\lim _{n \rightarrow \infty} P\left\{\frac{M_{n}-d_{n}}{c_{n}} \leq x\right\} \rightarrow G(x) \sim \exp \left[-(1+\xi \chi)^{-\frac{1}{\xi}}\right]$

In this case, the value $1+\xi\left(\frac{x-\mu}{\sigma}\right)>0, x_{i}$ is the realisation of the independent random variable, which is distributed Pareto with unknown parameters $\xi$ and $\sigma$ (Jindrová and Pacáková, 2019).

This distribution has three parameters, namely:

1. Location parameter $\mu$, which shifts distribution left/right.

2. The scale parameter $\sigma$, which determines the distribution of data.

3. The shape parameter $\xi$, which determines the shape of the distribution.

When formed into a standard model, $G(x)$ is one of the non-degenerate distributions (Rébillat et al., 2018).

1. Gumbel distribution

$$
G(x)=\exp \left\{-\exp \left[\left(\frac{x-d}{c}\right)\right]\right\}, x \in R
$$

2. Frechet distribution

$$
G(x)=\left\{\begin{array}{c}
0, x \leq d \\
\exp \left\{-\left(\frac{x-d}{c}\right)^{-\alpha}\right\}, x>d
\end{array}\right.
$$

3. Weilbull distribution

$$
G(x)=\left\{\begin{array}{c}
\exp \left\{-\left(\frac{x-d}{c}\right)^{-\alpha}\right\} x<d \\
0, x \geq d
\end{array}\right.
$$


The function of Gumbel, Frechet, and Weibull distribution combined into one generalised extreme value (GEV) distributions family with the following equation.

$$
F(x)=\exp \left\{-\left[1+\xi\left(\frac{x-\mu}{\sigma}\right)\right]^{-\frac{1}{\xi}}\right\}
$$

\subsection{Peak Over Threshold Method}

The POT method is an approach that identifies extreme values through observational data that exceeds a certain threshold value. One or more extreme values in a particular block or period will be generated by the POT Method, which refers to the Generalised Pareto Distribution. The main concept of this method is to use thresholds to separate values that are considered extreme to all data and create a model for extreme values by modelling the tail distribution of all values that exceed this threshold. The Peak Over Threshold (POT) approach provides a good solution because more data is retrieved, so it can be used to model extreme values even though the amount of data held is very limited. Modeling using the Peak Over Threshold method was adopted from Generalized Pareto Distribution (GPD) (Gharib et al., 2017). For example: $x_{1}, x_{2}, \ldots, x_{n}$ is a sequence of unprocessed observations from an $F(x)$ distribution. For example, given a threshold or a high threshold u, assuming $x_{(1)}, x_{(2)}, \ldots, x_{(n)}$ is observational data that exceeds the threshold $\mathrm{u}$, define $x_{i}=x_{(i)}-u$ for $i=1,2,3, \ldots, k$, for the large $\mathrm{u}$ threshold. Generalised pareto distribution is defined as a distribution limit that is above the $u$ threshold. The conditional distribution function of the variable $Y=(X-u \mid X>u)$ approaches.

$F(y)=1-\left(1+\frac{\xi(y)}{\sigma}\right)^{-\frac{1}{\xi}}$

where $\left\{y: y>0\right.$ and $1+\frac{\xi(y)}{\sigma}>0$

The equation above is a Generalised Pareto Distribution family (GPD) (Jindrová \& Pacáková, 2019). The opportunity density function for GPD is as follows (by returning the variable $y$ to the $x$ variable).

$f(x, \sigma, \xi)=\left\{\begin{array}{c}\frac{1}{\sigma}\left(1+\frac{\xi x}{\sigma}\right)^{\frac{1}{\xi}-1}, \xi \neq 0 \\ \frac{1}{\sigma} \exp \left(-\frac{x}{\sigma}\right), \xi=0\end{array}\right.$

where $0 \leq x<\infty$ if $\xi \geq 0$ and $0 \leq x<-\frac{\sigma}{\xi}$, if $\xi<0$.

GPD has two parameters, namely the form parameter $(\xi)$ and the scale parameter $(\sigma)$. There are three types of distribution in GPD. Type 1 has an exponential distribution if $\xi=0$. Type 2 has a Pareto distribution if $\xi>0$. Type 3 has a beta distribution if $\xi<0$. The greater the value $\xi$, the distribution will have a tail that is getting fatter so that the chances of extreme values are even greater.

The method used to measure risk is Conditional Value-at-Risk (CVaR). CVaR was first introduced in (Rébillat et al., 2018). $\mathrm{CVaR}$ is the average loss based on the worst-case scenario, which is a coherent measure of risk and can work on data that is normally or not normally distributed.

Definition of Value-at-Risk (Pribadi et al., 2019). Let X be a random variable with a cumulative distribution function FX(x). Value-at-Risk (VaR) of $\mathrm{X}$ with a confidence level $\alpha$ is

$\operatorname{VaR}_{\alpha}(X)=\min \left\{x \mid F_{x}(x) \geq \alpha\right\}$

The above equation represents the lower percentile of the random variable $\mathrm{X}$.

Definition of Conditional Value-at-Risk. For random variables with continuous distribution functions, CVaR of X with a level of confidence $\alpha$ is the average of the generalised $\alpha$ tail distribution: 
$\operatorname{CVaR}_{\alpha}(X)=\int_{-\infty}^{\infty} z d F_{X}^{\alpha}(z)$

where

$F_{X}^{\alpha}(z)=\left\{\begin{array}{cc}0, & , z<\operatorname{VaR}_{\alpha}(X) \\ \frac{F_{X}(z)-\alpha}{1-\alpha}, & z<\operatorname{VaR}_{\alpha}(X)\end{array}\right.$

For general distribution, for example, upper $C V a R_{\alpha}$ is $\operatorname{CVaR}_{\alpha}^{+}(X)=E\left[X \mid X>\operatorname{VaR}_{\alpha}^{+}(X)\right]$ then $C V a R_{\alpha}(X)$

For general distribution, for example, upper $\operatorname{VaR}_{\alpha}(X)$ and $C V a R_{\alpha}^{+}(X)$

$$
\operatorname{CVaR}_{\alpha}(X)=\lambda_{\alpha}(X) \operatorname{VaR}_{\alpha}(X)+\left(1-\lambda_{\alpha}(X)\right) C \operatorname{VaR} R_{\alpha}^{+}(X)
$$

where

$$
\lambda_{\alpha}(X)=\frac{F_{X} \operatorname{VaR}_{\alpha}(X)-\alpha}{1-\alpha}
$$

\subsection{Estimation of GPD parameters with Maximum Likelihood Estimation}

The value of the parameter vector is estimated using the Maximum Likelihood Estimator (MLE) principle, which maximises the likelihood function. The likelihood function is the probability of observational data which is described as a function of parameters (Coles., 2001). Thus, the likelihood function is defined by swapping the roles of the data vector and the parameter vector. In GEV, the likelihood functions $L\left(\mu, \sigma, \xi \mid x_{1}, x_{2}, \ldots, x_{n}\right)$ describe the possibilities of parameters $\mu, \sigma$, and $\xi$ with known data $x_{1}, x_{2}, \ldots, x_{n}$ (Myung, 2003). The likelihood function is obtained by multiplying the opportunity density function. Following is the equation of the likelihood function of GEV (De Zea Bermudez and Kotz, 2010).

$$
L\left(\mu, \sigma, \xi \mid x_{1}, x_{2}, \ldots, x_{n}\right)=\prod_{i=1}^{n} f\left(\mu, \sigma, \xi, x_{i}\right) .
$$

For simplifying the calculation, parameter estimation with MLE can be generated by making the transformation of the function in the form of natural logarithms, namely, $\ln L\left(\mu, \sigma, \xi \mid x_{1}, x_{2}, \ldots, x_{n}\right)$. It is because the log-likelihood function is monotonically related to the likelihood function so maximising the log-likelihood function also means maximising the likelihood function. Assuming a differentiable $\log$-likelihood function, then $\xi, \sigma$, and $\mu$ exist and satisfy the following partial differential equation.

$$
\begin{aligned}
& \frac{\partial \ln L\left(\mu, \sigma, \xi \mid x_{1}, x_{2}, \ldots, x_{n}\right)}{\partial \xi} \\
& \frac{\partial \ln L\left(\mu, \sigma, \xi \mid x_{1}, x_{2}, \ldots, x_{n}\right)}{\partial \sigma} \\
& \frac{\partial \ln L\left(\mu, \sigma, \xi \mid x_{1}, x_{2}, \ldots, x_{n}\right)}{\partial \mu}
\end{aligned}
$$

It also satisfies GPD and the likelihood function of GPD is as follows.

$$
L\left(\sigma, \xi \mid x_{1}, x_{2}, \ldots, x_{n}\right)=\prod_{i=1}^{n} f\left(\sigma, \xi ; x_{i}\right)
$$

By assuming the Eq. (10), it's differentiable. There are $\xi$ and $\sigma$ that satisfy the following differentiable equation (Myung, 2003).

$$
\frac{\partial \ln L\left(\sigma, \xi \mid x_{1}, x_{2}, \ldots, x_{n}\right)}{\partial \sigma}
$$


$\frac{\partial \ln L\left(\sigma, \xi \mid x_{1}, x_{2}, \ldots, x_{n}\right)}{\partial \xi}=0$

Estimated value is obtained, if the first derivative equation forms a closed-form equation. If the equation formed is not closed form, then an advanced numerical settlement for its completion (Rydman, 2008).

Weather and climate are symptoms or events that are quite close on earth. Each has similarities and differences. Weather is a state of the air that occurs in a place with a narrow time. At the same time, the climate is an average weather pattern that occurs for a relatively long period and covers a large area. Weather and climate have the same elements, namely sunlight which emits light and energy to the earth's surface, in the form of radiation. As the main source of geothermal energy, the amount of solar radiation reaching the earth reaches $47 \%$. The rest are in air particles, such as dust, water vapour, and clouds. Every place on earth has a different intensity of solar radiation. It is because of the transparency of the atmosphere, sunlight incidence angle, earth and sun distance, altitude, sea distance, wind. The temperature of the air, which is the heat or cold of an object. Air temperature or temperature is the temperature of the hot or cold air in a certain place and time. Air heating is obtained through two processes, namely: direct heating, consisting of reflection, diffusion, and absorption and indirect heating, consisting of conduction, convection, and diffusion (Raucci, 2019).

Factors that affect air temperature include atmospheric transparency, angle of sunlight, duration of exposure, distance of the Earth and the Sun, altitude and many others. Air pressure which is the weight of the air mass over a unit area. If air temperature can be measured with a thermometer, air pressure can be measured with a barometer. Weather and climate have fundamental differences, namely: Coverage of regions and observations about weather are narrower and limited, whereas coverage of regions and climate observations are broader. When observing the weather in an area can be done for 24 hours, while for the climate carried out for 11-30 years. Weather has properties that change rapidly and are unstable, whereas climate has properties that are stable and difficult to change. Predictions about the weather are easy to do, whereas climate forecasts are difficult.

\section{Results and Discussion}

The weather variables analysed were wind speed, maximum temperature, minimum temperature, and rainfall in Bandung Regency, West Java, Indonesia from 2008-2019. Productivity data were obtained from the Bandung District Agriculture Office in West Java Province, Indonesia in 2008-2019. Climate variable data presented in Table 1 and Table 2, and plotted in Fig. 1, while rainfall data are plotted in Fig. 2. Large data on rainfall variability is presented in Figure 2. From the results of the plot, it can be seen that the greatest rainfall is in the range of November, December, January, to April. Figure 2 shows the plot of average yields per month per planting period. The lowest yields occur around the month of January and December. This is certainly related to high rainfall in the month.

Table 1

Average Bandung Weather per month from 2008-2019.

\begin{tabular}{lcccccccccccc}
\hline & Jan & Feb & Mar & Apr & May & Jun & Jul & Aug & Sept & Oct & Nov & Dec \\
\hline Temperature $\left({ }^{\circ} \mathrm{C}\right)$ & 23.3 & 23.2 & 23.5 & 23.7 & 23.7 & 22.7 & 22.5 & 22.8 & 23.3 & 23.7 & 23.5 & 23.6 \\
Min Temperature $\left({ }^{\circ} \mathrm{C}\right)$ & 19.5 & 19.2 & 19.2 & 19.2 & 19 & 17.5 & 17 & 17 & 17.4 & 18.3 & 18.8 & 19.3 \\
Max Temperature $\left({ }^{\circ} \mathrm{C}\right)$ & 27.1 & 27.3 & 27.9 & 28.3 & 28.4 & 28 & 28 & 28.6 & 29.2 & 29.2 & 28.3 & 27.9 \\
Rainfall (mm) & 243 & 217 & 257 & 246 & 166 & 77 & 70 & 68 & 83 & 174 & 272 & 291 \\
Paddy Rice & 9.0 & 10.6 & 16.2 & 15.9 & 11.4 & \multirow{2}{*}{11.3} & 11.6 & \multirow{2}{*}{12.6} & 11.2 & 10.3 & 9.7 & 8.7 \\
Productivity (ton/ha) & & & & & & & & & &
\end{tabular}

${ }^{1}$ Source: Processed from BPS Regency data, West Java, 2020.

Table 2

Average Bandung Weather per semester from 2008-2019

\begin{tabular}{|c|c|c|c|c|c|}
\hline 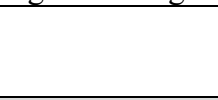 & $\begin{array}{c}\text { Paddy Rice } \\
\text { Productivity } \\
\text { (ton/ha) }\end{array}$ & $\begin{array}{l}\text { Wind velocity } \\
(\mathbf{k m} / \mathbf{h})\end{array}$ & $\begin{array}{c}\text { Max Temperature } \\
\left({ }^{\circ} \mathrm{C}\right)\end{array}$ & $\begin{array}{c}\text { Min Temperature } \\
\left({ }^{\circ} \mathrm{C}\right)\end{array}$ & $\begin{array}{c}\text { Rainfall } \\
\text { (mm) }\end{array}$ \\
\hline Total & 23.3 & 23.2 & 23.5 & 23.7 & 23.7 \\
\hline Average & 19.5 & 19.2 & 19.2 & 19.2 & 19 \\
\hline Maximum & 27.1 & 27.3 & 27.9 & 28.3 & 28.4 \\
\hline Minimum & 243 & 217 & 257 & 246 & 166 \\
\hline Variance & 9.0 & 10.6 & 16.2 & 15.9 & 11.4 \\
\hline Standard Deviation & 0.3 & 1.05 & 0.90 & 0.31 & 85.97 \\
\hline
\end{tabular}

The most dominant climate change is determined by the rainfall parameter. The growth of rice plants whose irrigation system depends on rain water will be influenced by the volume of rainfall each month. In this section, the effects of rainfall on the amount of rice produced will be explained. Data on rainfall, temperature, and rice production are defatted and the results of the meters are estimated using the MLE Maximum Likelihood Estimator with the help of easy fit software, 
presented in Table 3 and Table 5. While the statistical analysis results are presented in Table 4 and Table 6. Descriptive statistical results of the above yield data are presented in Table 3.

Rice productivity risk analysis is carried out using a Conditional Value at Risk (CVaR) risk measure. Based on the estimated model in Eq. (2), it was found that the risk of lowland rice productivity with climate variable variability is presented in Fig. 3 ., with a significant level of value of 0.9588 , the worst CVaR productivity occurred since the average productivity was 11.078 tons / ha. While the results of the risk analysis of climate variables on the productivity of inland rice are 8.7 tons / ha. This means that climate variability can cause the worst risk of CVaR of 0.17485 , where there is no yield of inland rice production in a given variable situation.

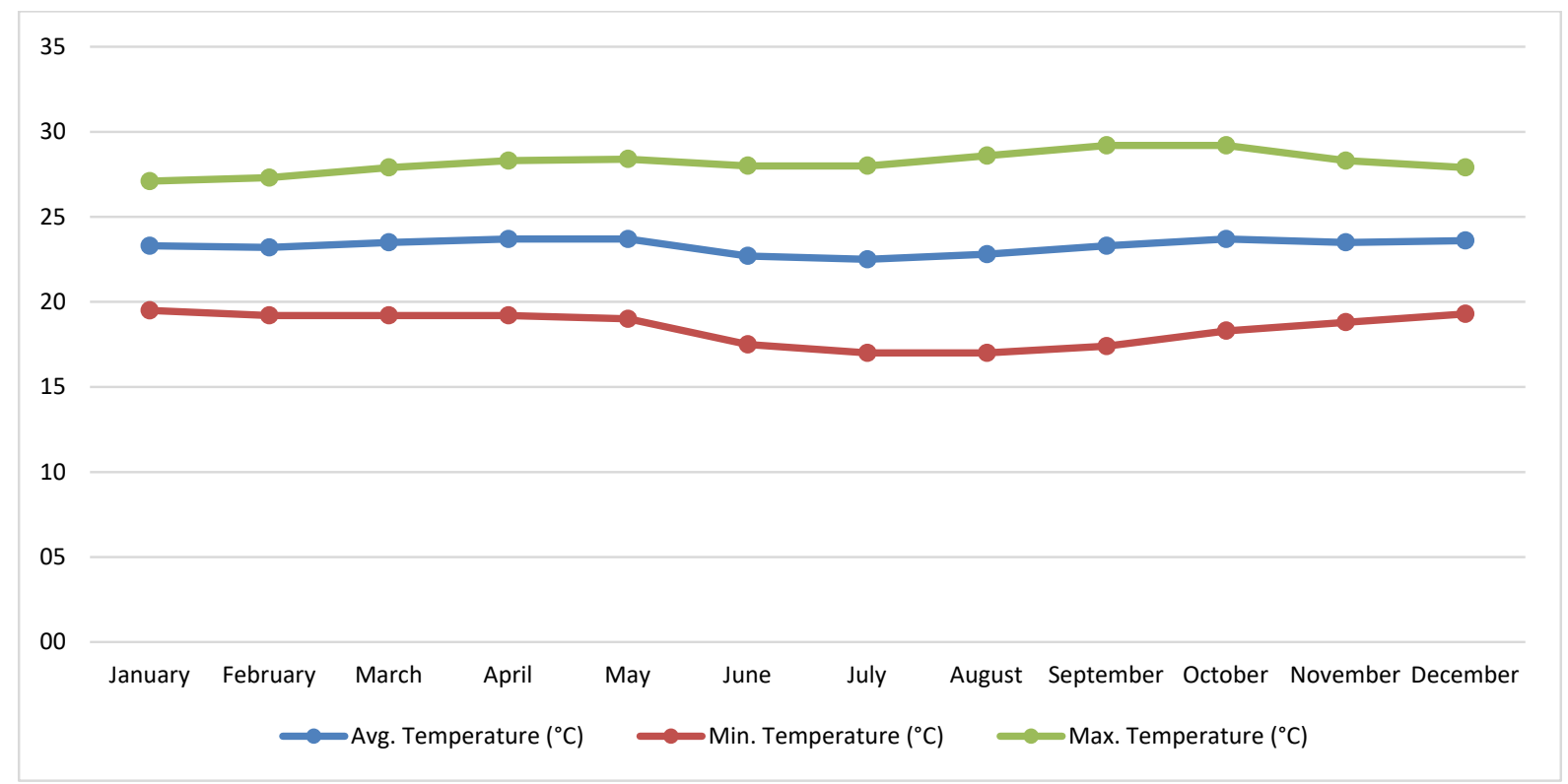

Fig. 1. The result of monthly temperature statistics at Bandung Regency 2008-2019

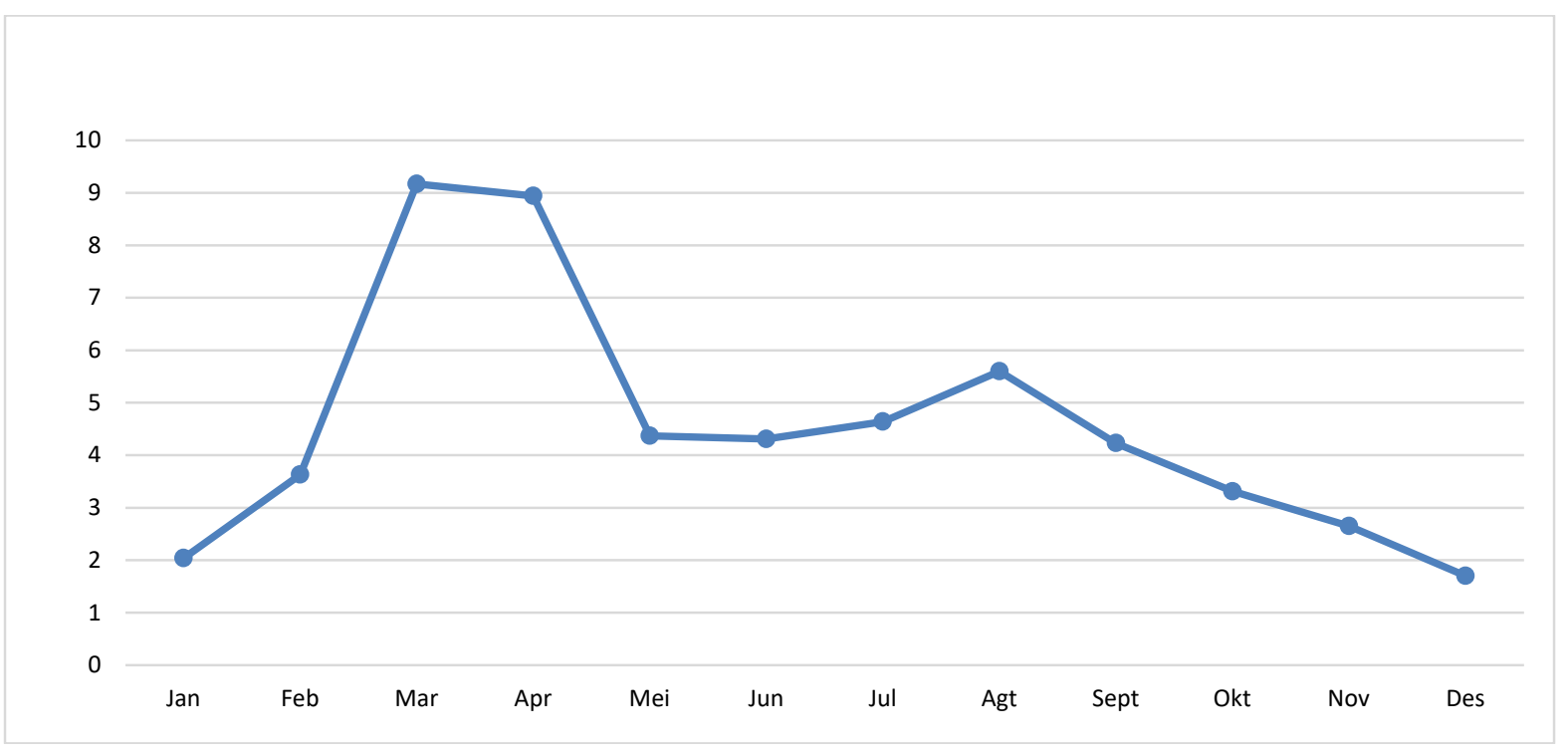

Fig. 2. The result of monthly rice production at Bandung Regency 2008-2019

Table 3

Descriptive statistics of rice yield data

\begin{tabular}{|c|c|c|c|}
\hline & \\
\hline Statistic & Value & Min & 8.7 \\
\hline Sample Size & 12 & $5 \%$ & 8.7 \\
\hline Range & 7.5 & $10 \%$ & 8.7 \\
\hline Range & 7.5 & $25 \%(\mathrm{Q} 1)$ & 9.7 \\
\hline Mean & 11.078 & $50 \%$ (Median) & 11.2 \\
\hline
\end{tabular}


358

\begin{tabular}{lccc} 
Variance & 3.7522 & $75 \%(\mathrm{Q})$ & 11.6 \\
Std. Deviation & 1.9371 & $90 \%$ & 12.6 \\
CVaR & 0.17485 & $95 \%$ & \\
Std. Error & 0.55918 & Max & \\
Skewness & 1.1938 & Min & 16.9 \\
Excess Kurtosis & 1.2945 & $5 \%$ & 8.7 \\
\hline
\end{tabular}

Table 4

Results of statistical analysis of yield data

\section{Gumbel Max}

Kolmogorov-Smirnov

Sample Size $=12$ Statistic $=0.13566$ P-Value $=0.95887$ Rank $=2$

\begin{tabular}{|c|c|c|c|c|c|}
\hline$\alpha$ & 0.2 & 0.1 & 0.05 & 0.02 & 0.01 \\
\hline Critical Value & 0.2957 & 0.33815 & 0.37543 & 0.41918 & 0.44905 \\
\hline Reject? & No & No & No & No & No \\
\hline \multicolumn{6}{|c|}{ Anderson-Darling } \\
\hline \multicolumn{6}{|c|}{ Sample Size $=12$ Statistics $=0.52578$ Rank $=5$} \\
\hline$\alpha$ & 0.2 & 0.1 & 0.05 & 0.02 & 0.01 \\
\hline Critical Value & 1.3749 & 1.9286 & 2.5018 & 3.2892 & 3.9074 \\
\hline Reject? & No & No & No & No & No \\
\hline
\end{tabular}

Table 5

Results of statistical analysis of rainfall

\begin{tabular}{lccc}
\hline \multicolumn{1}{c}{ Statistic } & Value & Percentile & Value \\
\hline Sample Size & 12 & Min & 68 \\
Range & 223 & $5 \%$ & 68 \\
Mean & 181.36 & $10 \%$ & 70 \\
Variance & 6725.5 & $25 \%(\mathrm{Q} 1)$ & 83 \\
Std. Deviation & 82.009 & $50 \%$ Median) & 217 \\
Coef. of Variation & 0.45218 & $75 \%(\mathrm{Q} 3)$ & 257 \\
Std. Error & 23.674 & $90 \%$ & 272 \\
Skewness & -0.26392 & $95 \%$ & 291 \\
Excess Kurtosis & -1.5245 & Max & 291 \\
\hline
\end{tabular}

Table 6

Results of statistical analysis of rainfall data

Gen. Extreme Value

\begin{tabular}{|c|c|c|c|c|c|}
\hline \multicolumn{6}{|c|}{ Kolmogorov-Smirnov } \\
\hline Sample Size & & & 12 & & \\
\hline Statistic & & & 0.19431 & & \\
\hline P-Value & & & 0.68702 & & \\
\hline Rank & & & 7 & & \\
\hline$\alpha$ & 0.2 & 0.1 & 0.05 & 0.02 & 0.01 \\
\hline Critical Value & 0.29577 & 0.33815 & 0.37543 & 0.41918 & 0.44905 \\
\hline Reject? & No & No & No & No & No \\
\hline \multicolumn{6}{|c|}{ Anderson-Darling } \\
\hline
\end{tabular}




\begin{tabular}{lccccc} 
Sample Size \\
$\begin{array}{l}\text { Statistic } \\
\text { Rank }\end{array}$ & & \multicolumn{5}{c}{12} \\
\\
$\alpha$ & 0.2 & 0.1 & 49818 & 0.01 \\
Critical Value & 1.3749 & 1.9286 & 2.5018 & 3.2892 & 3.9074 \\
\hline Reject? & No & No & No & No & No \\
\hline
\end{tabular}

\section{Conclusion}

Based on the results of the discussion of the risk of the effects of changes in climate variables consisting of temperature, wind speed, maximum temperature, minimum temperature and rainfall which have Generalised Extreme Value distribution on the yield of rice production with Gumbel Max distribution, it is significant to the amount of yield. The lowest yields occur around January and December. This is certainly related to high rainfall in the month.

\section{Acknowledgments}

The author would like to thank the Dean of the Faculty of Mathematics and Natural Sciences, Universitas Padjadjaran and the Directorate of Research and Community Service (DRPM), who have provided funding via the Universitas Padjadjaran Doctoral Dissertation Research Grant (RDDU), with a contract number: 5878/UN6.D/LT/2019.

\section{References}

Akter, S., Krupnik, T. J., Rossi, F., \& Khanam, F. (2016). The influence of gender and product design on farmers' preferences for weather-indexed crop insurance. Global Environmental Change, 38, 217-229.

Berhane, T., Shibabaw, N., Awgichew, G., \& Kebede, T. (2020). Option pricing of weather derivatives based on a stochastic daily rainfall model with Analogue Year component. Heliyon, 6(1), e03212.

Burns, C. B., \& Prager, D. L. (2018). Does Crop Insurance Influence Commercial Crop Farm Decisions to Expand? An Analysis Using Panel Data from the Census of Agriculture. Journal of Agricultural and Resource Economics, 43(18352018-706), 61-77.

Chicaíza, L., \& Cabedo, D. (2009). Using the Black-Scholes method for estimating high-cost illness insurance premiums in Colombia. Innovar, 19(33), 119-130.

Coles, S. (2001) An Introduction to Statistical Modeling of Extreme Values. London: Springer.

De Zea Bermudez, P., \& Kotz, S. (2010). Parameter estimation of the generalized Pareto distribution-Part II. Journal of Statistical Planning and Inference, 140(6), 1374-1388.

Gharib, A., Davies, E. G., Goss, G. G., \& Faramarzi, M. (2017). Assessment of the combined effects of threshold selection and parameter estimation of Generalized Pareto Distribution with applications to flood frequency analysis. Water, 9(9), 692.

Jindrová, P., \& Pacáková, V. (2019). Natural Catastrophe Models for Insurance Risk Management. WSEAS Transactions on Business and Economics, 16(1),1-12.

Kapsambelis, D., Moncoulon, D., \& Cordier, J. (2019). An Innovative Damage Model for Crop Insurance, Combining Two Hazards into a Single Climatic Index. Climate, 7(11), 125-132.

Martin, S. W., Barnett, B. J., \& Coble, K. H. (2001). Developing and pricing precipitation insurance. Journal of Agricultural and Resource Economics, 261-274.

Mcleman, R., \& Smit, B. (2006). Vulnerability to climate change hazards and risks: crop and flood insurance. Canadian Geographer/Le Géographe Canadien, 50(2), 217-226.

Myung, I. J. (2003). Tutorial on maximum likelihood estimation. Journal of Mathematical Psychology, 47(1), 90-100.

Okine, A. N. (2014), Pricing of Index Insurance Using Black-Scholes Framework: A Case Study of Ghana, Doctoral dissertation, Illinois State University.

Pramono, \& Sukono. (2017), Quadratic Investment Portfolio Without a Risk-Free Asset Based on Value-at-Risk, Journal of Engineering and Applied Sciences, 12, 4846-4850.

Pribadi, D. M.., Sukono, \& Riaman. (2019) Robust model of the combination of expectations and conditional valueat-risk from paddy farming risk management based on climate variability. International Journal of Innovation, Creativity and Change, 9(12), 110-124.

Raucci, G. L., Lanna, R., da Silveira, F., \& Capitani, D. H. D. (2019). Development of weather derivatives: evidence from the Brazilian soybean market. Italian Review of Agricultural Economics, 74(2), 17-28.

Rébillat, M., Hmad, O., Kadri, F., \& Mechbal, N. (2018). Peaks Over Threshold-based detector design for structural health monitoring: Application to aerospace structures. Structural Health Monitoring, 17(1), 91-107.

Reyes, C. M., Agbon, A. D., Mina, C. D., \& Gloria, R. A. B. (2017). Agricultural insurance program: Lessons from different country experiences (No. 2017-02). PIDS Discussion Paper Series.

Rydman, M. (2008) Application of the Peaks-Over-Threshold Method on Insurance Data. Project report, Uppsala University. 
Sturm, M., Goldstein, M. A., Huntington, H., \& Douglas, T. A. (2017). Using an option pricing approach to evaluate strategic decisions in a rapidly changing climate: Black-Scholes and climate change. Climatic Change, 140(3-4), 437449.

Stutley, C. (2011), Agricultural insurance in Asia and the Pacific Region. Bangkok: United Nations Food and Agricultural Organization.

Sukono, S., Albra, W., Zulham, T., Majid, I., Saputra, J., Subartini, B., \& Thalia, F. (2019). The Effect of Gross Domestic Product and Population Growth on CO2 Emissions in Indonesia: An Application of the Ant Colony Optimisation Algorithm and Cobb-Douglas Model. International Journal of Energy Economics and Policy, 9(4), 313.

Syahril, S., Masbar, R., Syahnur, S., Majid, S. A., Zulham, T., Saputra, J., \& Irmayani, I. (2019). The effect of global prices of crude palm oil, marketing margins and palm oil plantations on the environmental destruction: An application of Johansen cointegration approach. International Journal of Energy Economics and Policy, 9(4), 305.

Taib, C. M. I. C., \& Benth, F. E. (2012). Pricing of temperature index insurance. Review of development finance, 2(1), 2231.

Teklewold, H., Gebrehiwot, T., \& Bezabih, M. (2019). Climate smart agricultural practices and gender differentiated nutrition outcome: An empirical evidence from Ethiopia. World Development, 122, 38-53.

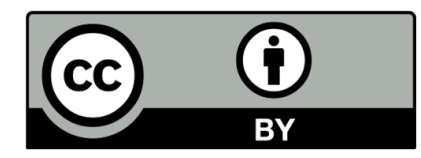

(C) 2021 by the authors; licensee Growing Science, Canada. This is an open access article distributed under the terms and conditions of the Creative Commons Attribution (CC-BY) license (http://creativecommons.org/licenses/by/4.0/). 